\title{
NOTAS SOBRE AS NEGOCIAÇÕES DA “CONVENÇÃO DO CRIME" E DOS PROTOCOLOS ADICIONAIS SOBRE TRÁFICO DE PESSOAS E CONTRABANDO DE MIGRANTES
}

\author{
Guilherme Mansur Dias ${ }^{1}$
}

\begin{abstract}
Este artigo reflete sobre o processo de negociação dos Protocolos Adicionais contra o Tráfico de Pessoas e o Contrabando de Migrantes no âmbito da Convenção das Nações Unidas Contra o Crime Organizado Transnacional (2000). Com base em dados construídos a partir de pesquisa qualitativa e de arquivo, discuto o papel destes documentos no deslocamento da temática migratória para o aparato criminal da ONU, bem como o consequente processo de aproximação entre mobilidade humana e justiça criminal no escopo da legislação internacional. O texto traz elementos acerca dos bastidores das referidas negociações, bem como dos distintos países e grupos de pressão envolvidos em tal processo.
\end{abstract}

Palavras-chave: tráfico de pessoas, contrabando de migrantes, Nações Unidas, migração, mobilidade humana.

\section{Introdução}

Este artigo aborda o processo de negociação da Convenção das Nações Unidas contra o Crime Organizado Transnacional e de seus Protocolos Adicionais relativos ao Tráfico de Pessoas e Contrabando de Migrantes. A partir da leitura das atas de negociação dos referidos Protocolos², bem como de entrevistas com funcionários da ONU e outros atores que participaram das negociações, discuto as implicações do destacamento institucional de discussões afetas à mobilidade humana para o aparato criminal das Nações Unidas.

Doutor em Antropologia Social, Unicamp. Rio de Janeiro, RJ, Brasil.

2 UNITED NATIONS ON DRUGS AND CRIME (UNODC). Travaux Préparatoires de las negociaciones para la elaboración de la Convención de las Naciones Unidas contra la Delincuencia Organizada Transnacional y sus Protocolos. 
As reflexões estão ancoradas no primeiro capítulo de minha tese de doutorado, que investigou a relação entre os campos migratórios e de segurança/ criminalidade, com base na reprodução de normativas e políticas internacionais sobre tráfico de pessoas e contrabando de migrantes ${ }^{3}$. A referida etnografia foi realizada entre os anos de 2011 e 2013 nas cidades de Viena e Brasília e contou com uma análise extensiva das práticas de Organismos Internacionais que atuam na intersecção entre os campos migratórios e de justiça criminal.

Neste texto, analiso de que forma a aproximação entre migração e crime/ segurança foi incorporada às discussões da referida Convenção, e o papel de determinadas delegações nacionais e grupos de pressão em tal processo. $\mathrm{Na}$ análise, ganha destaque o modo pelo qual as discussões sobre mobilidade humana foram alçadas à condição securitária no ambiente internacional na década de 1990, o que remete às preocupações de países do hemisfério norte em relação ao aumento da imigração em direção a seus territórios nacionais e supranacionais.

\section{Contextualizando a "Convenção do Crime" e seus Protocolos Adicionais}

Na introdução ao livro sobre as normativas das Nações Unidas na área criminal (1975-1998), Bassiouni e Vetere ${ }^{4}$ argumentam que a cooperação internacional contra o crime organizado data de pelo menos 1975, quando o 5 o Congresso do Crime da ONU enfocou as atividades criminais como negócio nos níveis nacional e transnacional. Desde aquela época, segundo os autores, a prioridade da comunidade internacional deteve-se no enfrentamento ao crime organizado, ao crime do colarinho branco e à corrupção ${ }^{5}$.

Em 1988, uma Conferência dos países-membros da ONU adotou a Convenção contra o Tráfico llícito de Entorpecentes e de Substâncias Psicotrópicas, que contou com um elevado número de ratificações e levou à criação de um Programa de Justiça Criminal e um órgão responsável por conduzir discussões sobre a temática das drogas no âmbito das Nações Unidas. A partir daí, foram criados o United Nations Fund for Drug Abuse Control (UNFDAC) e o United Nations International Drug Control Programme (UNDCP), instituições internacionais responsáveis pela formulação e implementação de políticas de enfrentamento ao tráfico de drogas e predecessores institucionais do United Nations on Drugs and Crime (UNODC).

3 DIAS, Guilherme M. Migração e Crime: desconstrução das políticas de segurança e tráfico de pessoas.

4 BASSIOUNI, M. Cherif, VETERE, Eduardo. Organized Crime: a Compilation of U.N. Documents 1975-1998.

5 Ibidem, p. xviii. 
Em 1990, as mudanças decorrentes da queda do muro de Berlim, com a independência de muitos países na Europa e na Ásia, trouxeram novas preocupações para as delegações presentes no $8^{\circ}$ Congresso do Crime, como o "crime organizado" e as "atividades criminais terroristas". Vale lembrar, todavia, que a demanda por cooperação, naquele momento, recaía sobretudo em questões relativas a extradição, assistência legal, transferência de prisioneiros e procedimentos penais, além do reconhecimento de julgamentos e provas produzidas em outros países ${ }^{6}$.

Com a Resolução 45/108 de 24 de dezembro de 1990, a Assembleia Geral decidiu criar o Programa das Nações Unidas de Prevenção ao Crime e de Justiça Criminal. Este programa, por sua vez, levaria à constituição da Comissão de Prevenção do Crime e Justiça Criminal, estrutura composta por representações governamentais de 40 países e vinculada ao Conselho Econômico e Social (ECOSOC) da ONU. Dentre os temas prioritários delegados à Comissão pelo ECOSOC e adotados pela Resolução 1992/22 estavam: “crime nacional e transnacional, crime organizado, crime econômico, incluindo lavagem de dinheiro, e o papel da legislação criminal na proteção do meio ambiente" ${ }^{\prime 7}$.

Nota-se que a abrangência de atuação da Comissão destacava a prática de crime organizado, crimes financeiros e até a questão ambiental, tratados a partir de uma perspectiva criminal, não se sobressaindo questões relativas à mobilidade humana. Embora se possa argumentar que tais temas fazem parte do guardachuva mais abrangente do "crime organizado", a não referência direta a tópicos como "tráfico de pessoas" e "contrabando de migrantes" na Resolução 1992/22 contrasta de maneira enfática com todas as priorizações, debates e medidas que viriam a ser adotados posteriormente no âmbito das discussões criminais na ONU.

A Comissão de Prevenção do Crime e Justiça Criminal seguiu, assim, trabalhando com a problemática do crime organizado transnacional e priorizando a questão dos delitos financeiros, que também era bastante debatida no âmbito da $\mathrm{OCDE}^{8}$. O trabalho daquela Comissão foi ganhando corpo até que a Assembleia Geral decidiu pautar a questão do crime organizado internacional de maneira prioritária. Isso levou à organização de reuniões e encontros, até chegar ao evento

6 Segundo Bassiouni e Vetere, "The rapid increase in the number of independent countries facing the growing expansion of criminal activities brought about the need for new international institutions that could enhance the effectiveness of crime prevention efforts at the national and international levels. On the recommendation of that Congress, the General Assembly made a substantive step toward strengthening international cooperation by adopting the Model Treaties on Extradition, on Mutual Assistance in Criminal Matters, on Transfer of Proceedings in Criminal Matters, and on Transfer of Supervision of Offenders Conditionally Sentenced or Conditionally Released" (ibidem, p. xviii).

Ibidem, p. xviii.

8 A Organização para a Cooperação e Desenvolvimento Económico é uma organização internacional composta por 34 países. A Organização foi criada em 1948 para ajudar a administrar o Plano Marshall na reconstrução da Europa do pós-guerra. Posteriormente, sua filiação foi estendida a alguns estados não-europeus. Informações adicionais em http://www.oecd.org/fr/. 
que, na interpretação de Bassiouni e Vetere, foi o mais relevante na história do Programa das Nações Unidas de Prevenção ao Crime e de Justiça Criminal: a Primeira Conferência Mundial sobre o Crime Organizado Transnacional, ocorrida em Nápoles, na Itália, de 21 a 23 de novembro de $1994^{9}$.

Dois meses após participar de um dos encontros preparatórios para esta Conferência em Viena, o juiz Giovanni Falcone foi assassinado pela máfia Cosa Nostra, perto de Palermo, fato que teria sensibilizado os participantes da Comissão, especialmente os representantes do governo e da sociedade italiana ${ }^{10}$. Em decorrência de sua morte, o governo da Itália ofereceu-se como anfitrião para a realização da Conferência de Nápoles e a Comissão se empenhou em realizá-la no período de um ano.

A Conferência, que contou com a participação de 2000 pessoas de 142 países diferentes, resultou na Declaração Política de Nápoles e no Plano de Ação Global contra o Crime Organizado Transnacional. Estes documentos são usualmente referidos como a base para a elaboração da Convenção do Crime, embora a ideia desta Convenção, lançada pela Declaração Política de Nápoles, tenha sido, à época, bastante contestada.

De acordo com Vlassis, os membros da Europa ocidental e de países como Austrália, Canadá, Nova Zelândia e Estados Unidos mostraram forte resistência inicial à ideia de uma nova Convenção Internacional sobre o tema. $\mathrm{O}$ assunto do "crime organizado" seria demasiado espinhoso para ser tratado no âmbito de um documento daquele porte, acarretando um número muito grande de dificuldades e desacordos conceituais e legais a serem negociados ${ }^{11}$.

De acordo com um interlocutor de pesquisa, o processo de convencimento dos Estados-membros foi demorado. Enquanto a maioria dos países em desenvolvimento mostrava-se disposta à elaboração da Convenção Internacional, os países desenvolvidos resistiam à proposta. $\mathrm{O}$ representante da Comissão disse que aquele tipo de decisão exigiria acordo entre os países e que "a Assembléia Geral procura evitar votações consideradas polêmicas e que podem dar vazão a questionamentos com relação à legitimidade do órgão"12.

9 BASSIOUNI, VETERE, op. cit., p. xix.

${ }^{10}$ Até hoje, o assassinato do juiz Giovanni Falcone é tido como um referencial importante para a ONU em ações de combate ao crime organizado. Em 18 de julho de 2012, o UNODC circulou uma nota rememorando dos 20 anos do assassinato dos juízes Paolo Borsellino e Giovanni Falcone pela máfia italiana e lembrou a influência que suas ideias continuariam a ter no enfrentamento ao crime organizado transnacional. Ver: UNODC. Chief praises murdered magistrates who helped found modern approach to organized crime.

11 VLASSIS, Dimitri. Overview of the provisions of the United Nations Convention Against Transnational Organized Crime and its Protocols, p. 481.

12 A legitimidade das Organizações Internacionais é uma questão sempre salientada por autores que se dedicam ao estudo dessas burocracias modernas. Mônica Herz e Andrea R. Hoffman (Organizações Internacionais: história e práticas) refletem sobre esta questão nos seguintes termos: "Para que possam realizar suas funções como fóruns produtores de normas e garantir aquiescência às mesmas, as 
De todo modo, a atitude reticente com relação à ideia da Convenção por parte dos países ricos modificou-se no final da década de 1990, quando um Comitê Ad Hoc instituído pela Assembleia Geral para lidar com a proposta de uma Convenção Internacional passou a trabalhar em um rascunho de documento proposto pelo governo da Polônia.

Neste ínterim, três Protocolos Adicionais, sugeridos para lidar com tipos de ofensa específicos, seriam negociados separadamente, ao mesmo tempo em que se consolidariam como textos integrantes da referida Convenção: o Protocolo contra a fabricação e uso ilícito de armas de fogo, o Protocolo contra o tráfico ilícito de migrantes e o Protocolo para prevenir, suprimir e punir o tráfico de pessoas. Em um ambiente afeto à discussão de questões criminais, tais temas foram particularmente pinçados e eleitos como prioritários nas discussões de cooperação internacional em matéria criminal, mesmo que não estivessem no radar das discussões criminais das décadas anteriores. Curiosamente, dois deles lidavam diretamente com a questão da mobilidade humana.

No caso do Protocolo relativo ao tráfico de pessoas, representantes da Argentina estavam há algum tempo discutindo a possibilidade de elaboração de uma nova Convenção contra o tráfico de menores. Eles haviam tentado incorporar este tema no escopo da Convenção sobre os Direitos das Crianças, sem, no entanto, obter o sucesso almejado. Provavelmente influenciada por grupos de defesa dos direitos de crianças e adolescentes, a delegação argentina optou por uma estratégia de mobilização da estrutura criminal da ONU para emplacar o debate sobre tráfico de menores ${ }^{13}$.

No caso da inclusão do Protocolo Contra o Contrabando de Migrantes, as ações dos governos austríaco e italiano contribuíram de maneira decisiva. A Áustria estava, no período, recebendo um afluxo considerável de imigrantes do leste em decorrência da derrocada do regime socialista, além do aumento nas solicitações de refúgio e asilo por cidadãos que fugiam dos conflitos na antiga lugoslávia. A preocupação com a chegada ou passagem dos estrangeiros pelo país deu espaço à reação xenofóbica e ao crescimento temeroso do Partido da Liberdade, de Jorg Haider, que encampou uma batalha ideológica contra a chegada de imigrantes.

Organizações Intergovernamentais Internacionais (OIGs) enfrentam o problema da legitimidade. Essa é uma questão presente na ação política de uma forma geral, mas as OIGs enfrentam dificuldades específicas como a ausência de uma cultura comum robusta ou da possibilidade de impor decisões com o uso da força, com exceção de casos extremos" (Ibidem, p. 25).

${ }^{13}$ Ainda que tenha tido papel central na negociação deste Protocolo, não é possível creditar à delegação argentina a responsabilidade pela difusão da agenda anti-tráfico no cenário internacional. As abordagens e perspectivas em torno de temáticas construídas como prioritárias internacionalmente dependem fundamentalmente de uma rede de financiadores que delimitarão a linguagem dos projetos e programas a serem financiados (ver DIAS, op. cit.). 
Neste processo de recrudescimento do discurso conservador, a associação dos estrangeiros ao "aumento da criminalidade" passou a ser automática. Foi justamente neste contexto que representantes do governo austríaco tomaram a iniciativa de apresentar à Comissão de Prevenção do Crime e Justiça Criminal o rascunho de uma Convenção destinada a tratar do "tráfico e transporte ilícitos de migrantes", enfocando, porém, a prerrogativa de combate aos supostos grupos criminosos envolvidos naquele tipo de crime.

No mesmo período, a Itália estava lidando com a chegada de um número significativo de imigrantes cruzando o mediterrâneo em barcos e pateras até a Lampedusa e outras regiões da costa do país. Além dos imigrantes provenientes de países do continente africano, as correntes migratórias de curdos, paquistaneses, iraquianos e chineses eram tidas como as mais significativas. Outra questão relevante para as autoridades italianas no período era a migração de albaneses pelo mar Adriático, que assumia proporções aparentemente significativas em decorrência dos conflitos nos Bálcãs.

Na década de 1990, a Itália já havia acionado a Organização Marítima Internacional (IMO) para que elaborasse diretivas a respeito do contrabando de migrantes, chegando a propor um rascunho de Convenção Multilateral para o Combate à Migração Ilegal pelo Mar. Este rascunho, entretanto, sofreu resistências por parte de outras delegações, que questionavam se aquela organização seria o fórum mais adequado para tratar de tal matéria. Com a iniciativa austríaca de apresentar o rascunho de uma Convenção sobre o tráfico e o transporte ilícito de migrantes, a Itália somou esforços, apresentando a proposta de Protocolo.

Em decorrência das propostas feitas, a decisão política que a Comissão passou a ter que tomar era como articular as negociações de quatro diferentes instrumentos que, de maneira súbita, emergiram como prioritários na agenda política internacional daquele momento.

Foi deste modo que tomou corpo a Convenção contra o Crime Organizado Transnacional, que seria assinada no ano 2000, contando com três Protocolos Adicionais que tratam dos temas anteriormente referidos. Esses delineamentos dão pistas de como questões relacionadas à mobilidade e circulação de pessoas passarão a ser tratadas no escopo das estruturas de segurança da ONU e como "tráfico de pessoas" e "contrabando de migrantes" tornar-se-iam referentes conceituais em um documento de repressão à criminalidade, o que levou à ênfase na repressão e não na proteção aos direitos humanos dos migrantes ${ }^{14}$.

Desde que foram assinados, a Convenção do Crime e os Protocolos Adicionais direcionados ao combate ao tráfico de pessoas e ao contrabando de imigrantes receberam significativa adesão e ratificações dos países membros

${ }_{14}$ JORDAN, Ann D. Human Rights or Wrong? The Struggle for a Rights-Based Response to Trafficking in Human Beings, p. 29. 
da ONU, principalmente quando comparados a outros instrumentos que se destinam à proteção dos direitos dos migrantes, como a Convenção Internacional sobre a Proteção dos Direitos de Todos os Trabalhadores Migrantes e dos Membros das suas Famílias.

Para melhor compreendermos o conteúdo que estas normativas internacionais assumiriam, bem como os efeitos que vieram a ter nas cruzadas internacionais anti-prostituição e anti-imigração ${ }^{15}$, é importante se ater à dinâmica do processo de negociação empreendido. Farei a seguir uma análise dos Protocolos contra o Tráfico de Pessoas e o Contrabando de Migrantes, buscando visualizar os interesses e perspectivas disputados naquele momento, especialmente no que se refere ao tema das migrações e à sua vinculação às questões de segurança e criminalidade na legislação internacional.

\section{Protocolo para Prevenir, Suprimir e Punir o Tráfico de Pessoas, especialmente Mulheres e Crianças}

Tomando por referência a (re)emergência contemporânea dos debates sobre tráfico de pessoas no cenário internacional, pode-se dizer que as discussões acerca do tema voltaram a ganhar força e destaque durante a década de 1990, através da realização de distintas conferências e encontros ${ }^{16}$. Estes distintos eventos ajudaram a mobilizar governos e representantes de diferentes países em torno do tema do tráfico de pessoas, o que não se deu sem tensões ou divergências ideológicas ${ }^{17}$.

${ }^{15}$ AUSSERER, Caroline. Controle em nome da proteção: análise crítica dos discursos sobre o tráfico internacional de pessoas; KEMPADOO, Kamala. Mudando o debate sobre o tráfico de mulheres; DOEZEMA, Jo. Now you see her, now you don't: sex workers at the UN Trafficking Protocol negotiation; PISCITELLI, Adriana G. Procurando vítimas do tráfico de pessoas: brasileiras na indústria do sexo na Espanha.

${ }^{16}$ Segundo Castilho, "Em 1992, a ONU lança o Programa de Ação para a Prevenção da Venda de Crianças, Prostituição Infantil e Pornografia Infantil. A necessidade de um processo de revisão se fortalece na Conferência Mundial dos Direitos Humanos (1993), cuja Declaração e Programa de Ação de Viena salientam a importância da 'eliminação de todas as formas de assédio sexual, exploração e tráfico de mulheres'. Daí o Programa de Ação da Comissão de Direitos Humanos para a Prevenção do Tráfico de Pessoas e a Exploração da Prostituição (1996) (...) Em 1994, a Resolução da Assembléia Geral da ONU definiu o conceito de tráfico (...) A Quarta Conferência Mundial sobre a Mulheres, em Beijing (1995), aprovou uma Plataforma de Ação (...) o Estatuto do Tribunal Penal Internacional (1998) definiu os crimes internacionais de escravidão sexual e de prostituição forçada contra a humanidade e de guerra (...) A Convenção Interamericana de 1998 sobre o Tráfico Internacional de Menores conceituou o tráfico internacional de pessoas (...)" (CASTILHO, Ela W. V. Tráfico de pessoas: da Convenção de Genebra ao Protocolo de Palermo).

17 Na luta pela definição de tráfico, inclusive durante as negociações de Palermo, Doezema (op. cit.) destaca dois grupos principais de pressão, ambos articulados a paradigmas feministas diferenciados: o primeiro, Human Rights Caucus, liderado pela ONG GAATW (Global Alliance againstTraffic in Women), pelas organizações de direitos humanos IHRLG (International Human Rights Law Group) e AWHRC (Asian Women's Human Rights Council) e por grupos que representavam as trabalhadoras do sexo; e o segundo, que reforçava a defesa da perspectiva "abolicionista", coordenado pela ONG CATW (Coalition Against Trafficking in Women) e que tinha uma posição mais conservadora 
Com base no trabalho de Doris Buss e Didi Hermannn, Elizabeth Bernstein $^{19}$ salienta como os diferentes encontros promovidos pelas Nações Unidas na década de 1990 estimularam o avanço de setores evangélicos norteamericanos sobre a pauta dos direitos humanos no plano internacional. Em seu argumento, a autora reitera que a eficácia na elaboração e reprodução das políticas anti-tráfico no mundo contemporâneo é produto do cruzamento entre duas perspectivas políticas que tiveram incidência no contexto norte-americano, e que se difundiram através de projetos políticos empreendidos no nível global: 1) a guinada para a direita por parte de feministas e outros setores liberais seculares, que passaram a endossar as políticas carcerárias, em detrimento de modelos redistributivos de justiça e 2) a guinada em direção à esquerda por parte de lideranças jovens evangélicas, que optaram por abrir mão de pautas isolacionistas relacionadas ao aborto e ao casamento gay para disseminarem uma teologia da justiça social orientada para o ambiente internacional ${ }^{20}$.

Se, por um lado, no início dos anos 2000, a agenda feminista contra a violência sexual estava sendo exportada como parte das políticas de direitos humanos dos Estados Unidos, por outro, os jovens evangélicos, que continuavam se opondo ao casamento gay e ao aborto, reviram suas estratégias e optaram por evitar controvérsias em torno dessas disputas, reforçando o apoio a lutas tidas como consensuais, tais como aquecimento global, tráfico de pessoas e HIV/ $\mathrm{AIDs}^{21}$. Essa aliança ajudaria a solidificar o paradigma das políticas carcerárias mundo afora, sendo o movimento anti-tráfico exemplar do domínio de certo ativismo feminista no qual um marco criminal prevaleceu sobre os modelos de justiça distributiva.

Nas negociações do Protocolo Anti-Tráfico, essas diferentes perspectivas seriam reproduzidas por delegações nacionais específicas, embora não se possa creditar a essas delegações a responsabilidade exclusiva pelas abordagens e decisões tomadas. Nesse sentido, a delegação argentina fez uma proposta na qual a preocupação mais enfática endereçava conjuntamente as questões do tráfico de mulheres e crianças. Esta proposta referia-se somente ao tráfico de mulheres e crianças consideradas "vulneráveis" àquele tipo de prática criminal, posição que subentendia o lobby do grupo CATW, que tentava reunir o tráfico de mulheres e crianças sob uma única categoria.

diante do tema, elencando a prostituição como fonte do problema (DOEZEMA, op. cit., p. 68).

${ }^{18}$ BUSS, Doris, HERMAN, Didi. Globalizing Family Values: The Christian Right in International Politics.

${ }^{19}$ BERNSTEIN, Elizabeth. Militarized Humanitarianism Meets Carceral Feminism: The Politics of Sex, Rights, and Freedom in Contemporary Antitrafficking Campaigns. BERNSTEIN, Elizabeth. Carceral politics as gender justice? The "traffic in women" and neoliberal circuits of crime, sex, and rights.

20 BERNSTEIN, Militarized Humanitarianism..., op. cit., p. 51.

${ }^{21}$ Ibidem, p. 60. 
Subjacente a essa estratégia, ecoava a posição de determinados argumentos feministas ocidentais que compreendem a opção pelo trabalho sexual como falta de discernimento sobre as implicações deste trabalho. Por entenderem que a prostituição é uma atividade que viola, de forma intrínseca, a dignidade das mulheres, sua extinção - como no caso da prostituição infantil - seria a única alternativa a se considerar ${ }^{22}$.

Esta proposta argentina foi substituída pela dos EUA, que reconhecia a situação especialmente vulnerável de mulheres e crianças, mas pretendia ser aplicável ao tráfico de qualquer pessoa. Embora a delegação norteamericana também tenha sofrido fortes pressões de grupos religiosos e do lobby abolicionista ${ }^{23}$, sua proposta alternativa acabou por não equacionar de maneira direta tráfico e prostituição.

De todo modo, ainda que os interesses da proposta argentina se alinhassem mais claramente à perspectiva abolicionista, as polêmicas em torno da aproximação entre prostituição e tráfico também se observariam na primeira proposta de definição de "exploração sexual" feita conjuntamente por Estados Unidos e Argentina.

Segundo as atas de negociação, a maioria das delegações propôs a supressão da palavra "forçada" naquele texto. Outras delegações assinalaram que as vítimas poderiam ter dificuldades para provar que haviam sido "forçadas". Todavia, várias outras delegações expressaram a opinião de que seria essencial distinguir entre as vítimas da prostituição e aquelas que escolhiam dedicar-se à prostituição $^{24}$.

Para Doezema ${ }^{25}$, inicialmente, o lobby do Human Rights Caucus apoiava-se na ideia de que o termo "prostituição" deveria ser eliminado da definição daquele Protocolo. O grupo argumentava que as medidas e legislações anti-tráfico teriam sido historicamente utilizadas contra as trabalhadoras do sexo e não contra os supostos "traficantes". Por não conseguir a eliminação do termo "prostituição" durante as negociações, o grupo lutou por estabelecer uma diferenciação enfática entre trabalhadoras sexuais e vítimas de tráfico. A partir daí, nada parece ter rendido mais polêmica do que a discussão em torno da noção de consentimento.

Estados, como Bélgica e Vaticano sustentavam o argumento do grupo CATW de que uma pessoa jamais poderia consentir com a prostituição. Por outro lado, o lobby do Human Rights Caucus concentrou-se na ideia de que era possível consentir com tal atividade, diferenciando entre "trabalhadora do sexo" e "vítima de tráfico". Depois de uma discussão exaustiva, que tomou quase todas

\footnotetext{
${ }^{22}$ DOEZEMA, op. cit., p. 73.

${ }^{23}$ Ibidem, p. 78.

${ }^{24}$ UNODC. Travaux Préparatoirs..., op. cit., p. 358.

${ }^{25}$ DOEZEMA, op. cit.
} 
as sessões da negociação do Protocolo, as delegações presentes acordaram uma solução de compromisso.

Nesta definição, o uso da força ou coerção foi incluído como um elemento essencial (posição do grupo Human Rights Caucus), mas as noções de tráfico e prostituição seriam ainda articuladas de maneira confusa e ambígua ${ }^{26}$. Assim, os termos "exploração da prostituição de outrem" e "exploração sexual" continuaram sem definição no Protocolo ou em qualquer outra lei internacional, mesmo que tais termos tivessem sido encetados para se colocar fim ao longo debate em torno da noção de consentimento na prostituição voluntária.

No que tange ao conteúdo da exploração, o documento alude à exploração da prostituição por outrem, ou a outras formas de exploração sexual, além do trabalho forçado, escravidão ou práticas análogas à escravidão, à servidão e à remoção de órgãos. Quanto à questão do consentimento, o Protocolo afirma tratar-se de algo irrelevante se as vítimas forem sujeitadas a exploração por qualquer dos meios expressos na alínea "a", ou ainda quando se trata de pessoa com idade inferior a 18 anos.

Analisando os estudos críticos em relação ao Protocolo de Palermo, Piscitelli enfatiza que o documento assume uma posição de neutralidade em relação ao debate em torno da prostituição. Isso fica particularmente claro em termos de crucial importância para a definição de situações de tráfico, como "a exploração da prostituição de outrem ou outras formas de exploração sexual", "servidão", "outras formas de coerção", "abuso de poder" ou de uma "posição de vulnerabilidade", carentes de precisão conceitual.

Para a antropóloga, em função das ambiguidades e da falta de clareza conceitual existentes em termos-chave do Protocolo ${ }^{27}$, ele acaba sendo instrumentalizado em função de interesses particulares dos Estados-Nação que o ratificaram, interesses que, particularmente no contexto europeu, direcionam-se à repressão à imigração indocumentada e à prostituição ${ }^{28}$.

$\overline{{ }^{26} \mathrm{O} \text { art. 3oㅡ, alínea a }}$, do Protocolo de Palermo considera tráfico "o recrutamento, o transporte, a transferência, o alojamento ou o acolhimento de pessoas, recorrendo à ameaça ou ao uso da força ou a outras formas de coação, ao rapto, à fraude, ao engano, ao abuso de autoridade ou de situação de vulnerabilidade ou à entrega ou aceitação de pagamentos ou benefícios para obter o consentimento de uma pessoa que tem autoridade sobre outra, para fins de exploração. A exploração deverá incluir, pelo menos, a exploração da prostituição de outrem ou outras formas de exploração sexual, o trabalho ou serviços forçados, a escravatura ou práticas similares à escravatura, a servidão ou a extração de órgãos". A alínea $\underline{b}$ do referido artigo, por sua vez, diz que "o consentimento dado pela vítima de tráfico de pessoas a toda forma de exploração intencional descrita na alínea a do presente artigo não será levada em conta quando se houver recorrido a qualquer dos meios enunciados na referida alínea".

${ }^{27}$ PISCITELLI, Adriana G. Entre as máfias e a ajuda: a construção de conhecimento sobre tráfico de pessoas, p. 46.

${ }^{28}$ Entrevista realizada em 2009 para o estudo "Jornadas Transatlânticas: uma pesquisa exploratória sobre o tráfico de seres humanos do Brasil para Itália e Portugal" (DIAS, Guilherme M., SPRANDEL, 
Outra constatação da leitura das atas de negociação é o desequilíbrio patente entre as discussões de medidas de proteção e assistência às vítimas de tráfico e aquelas destinadas a estabelecer mecanismos de cooperação entre as autoridades estatais para perseguição e punição aos criminosos. Durante a discussão do artigo 6oa aliás, único artigo dedicado à assistência e proteção das vítimas de tráfico, algumas delegações reiteraram sua vontade de propor um equilíbrio maior entre, de um lado, a proteção e assistência às pessoas vítimas de tráfico e, de outro, as medidas de repressão ${ }^{29}$.

Para Anne Gallagher ${ }^{30}$, o Protocolo contém um número de medidas de proteção às vítimas, mas boa parte delas é opcional. Além disso, tais discussões surgiram mais como reação às discussões criminais do que como um enfoque particular e cuidadoso acerca do problema ${ }^{31}$.

Deste modo, fica evidente que a prioridade do Protocolo era a questão do combate às máfias e quadrilhas organizadas. O desequilíbrio entre as medidas de "repressão" e "assistência às vítimas" está dado de antemão, sendo a preocupação com as vítimas colocadas somente a posteriori e como forma de se angariar denúncias. Enquanto os artigos 10, 11, 12 e 13 do texto do Protocolo tratam, por exemplo, do "intercâmbio de informações e capacitações", "medidas fronteiriças", "segurança e controle dos documentos" e "legitimidade e validade dos documentos", somente o artigo $6^{0}$ será dedicado à assistência e proteção às vítimas de tráfico.

Salta aos olhos também a participação da Comunidade Europeia no pedido de harmonização do artigo sobre "medidas fronteiriças" do Protocolo Anti-Tráfico com os artigos 9 e 11 do projeto revisado do Protocolo contra o Contrabando de Migrantes $^{32}$. A proposta inicial de "controles fronteiriços" do artigo 9ㅇ, feita por Argentina e Estados Unidos, contava com apenas duas alíneas, mas em função da participação da delegação europeia, incorporou detalhes e outras quatro alíneas bastante restritivas à circulação de pessoas ${ }^{33}$.

Marcia A. Transatlantic Journeys: na exploratory research on human trafficking from Brazil to Italy and Portugal).

${ }^{29}$ UNODC. Travaux Préparatoirs..., op. cit., p. 389.

${ }^{30}$ GALLARGHER, Anne. Trafficking, smulggling and human rights: tricks and treaties.

31 De acordo com um representante brasileiro que participou da negociação do Protocolo, "A questão de assistência às vítimas foi surgindo durante as discussões. A ideia da Convenção era, basicamente, atacar o crime e seus praticantes: as quadrilhas organizadas. A discussão das vítimas veio um pouco depois, junto com os debates. Mas isso veio porque um dos problemas relacionados a esses crimes era a falta de denúncia. E esta falta de denúncia ocorria por medo ou por vergonha. Então, haveria que se ter uma maneira de trabalhar a questão das vítimas, para elas se sentirem tranqüilas para denunciar" (Entrevista, Brasília, 19/11/2009).

32 UNODC. Travaux Préparatoirs..., op. cit., p. 434.

${ }^{33}$ Refiro-me às alíneas 2, 3, 4 e 5 do art. 9o: "2. Los Estados Parte adoptarán medidas [legislativas o de otra índole] [apropiadas] para impedir que los medios de transporte empleados por transportistas comerciales se utilicen para la comisión de los delitos abarcados por el artículo 3 del presente Protocolo. 
Nestas alíneas, destacam-se medidas para que as empresas que fazem o transporte de pessoas atuem na fiscalização dos documentos dos passageiros, checando sua validade e status legal, com a criação de sanções e multas aos que desrespeitarem tais medidas. Outra previsão proposta diz respeito à atuação dos Estados Parte no sentido de revogar ou negar vistos (ou negar a entrada) a pessoas que estejam envolvidas com o delito definido pelo Protocolo.

Com essas proposições, os representantes da Comunidade Europeia buscaram enxertar no texto do Protocolo medidas mais vigorosas para o controle da circulação de estrangeiros. Com pouca reação das demais delegações presentes na negociação, os Estados transferiam às empresas de transporte nele sediadas a responsabilidade sobre a adoção de medidas diversas para evitar que viajantes e potenciais migrantes seguissem seu curso sem serem melhor controlados.

Vale reiterar que as polêmicas em torno da prostituição e das medidas de controle migratório já estavam bastante bem delineadas nas negociações do Protocolo Anti-Tráfico. Não causa surpresa, portanto, o fato da decisão de se deslocar para a estrutura criminal da ONU temas afetos à mobilidade humana ter plasmado discussões sobre migração, segurança e criminalidade, tornando-os aparentemente indissociáveis.

\section{Protocolo contra o tráfico ilícito de migrantes por terra, mar e ar}

Conforme salientado anteriormente, Áustria e Itália desempenharam um papel decisivo na proposição do Protocolo Contra o Tráfico llícito de Migrantes por Terra, Mar e Ar, também conhecido como Protocolo contra o Contrabando de Migrantes. Foram estes países que propuseram a inclusão de um Protocolo específico sobre o tema no escopo da Convenção do Crime, após seus representantes já terem atuado na formulação de medidas contra o contrabando de migrantes no âmbito da Organização Marítima Internacional (OMI) ${ }^{34}$.

\footnotetext{
3. Entre esas medidas se preverá, cuando proceda, y sin perjuicio de las convenciones internacionales aplicables, la obligación de los transportistas comerciales, incluidas las compañías de transporte o los propietarios o explotadores de naves o vehículos, de cerciorarse de que todos los pasajeros que viajen por [tierra] [tierra, excepto por ferrocarril] [carretera], mar o aire cuentan con pasaporte válido y, de ser necesario, visado o cualquier otro documento requerido para entrar legalmente en el Estado receptor. 4. Los Estados Parte adoptarán las medidas necesarias, de conformidad con su derecho interno, para prever sanciones en caso de incumplimiento de la obligación estipulada en el párrafo 3 del presente artículo. [Esas sanciones podrán consistir, entre otras cosas, en multas o medidas de incautación de los vehículos u otros medios de transporte utilizados]. 5. Los Estados Parte considerarán la posibilidad de adoptar medidas que permitan [de conformidad con su derecho interno] ly en los casos en que proceda] [revocar o denegar visados] [denegar la entrada] a personas [incluso funcionarios extranjeros] [que se sepa con fundamento razonable que están involucradas] [involucradas] en delitos abarcados en el presente Protocolo" (ibidem, p. 431-432).

${ }^{34}$ A OMI havia adotado em 1998 medidas contra práticas perigosas relacionadas ao contrabando e transporte de migrantes por mar, por meio do Comitê de Seguridade Marítima no documento MSC/Circ.896, assim como no documento A/AC.254/CRP.3. Durante os trabalhos preparatórios, no entanto, algumas delegações posicionaram-se com a assertiva de que tais documentos "podrían
} 
Durante as negociações do Protocolo, várias polêmicas que se seguiram diziam respeito à maior ou menor abrangência da definição de "smuggling"35 e do dilema que se colocava entre a criminalização de determinadas práticas de mobilidade que ameaçavam o princípio de livre circulação de pessoas e os direitos humanos dos migrantes. Foi em torno deste dilema que as diferentes delegações e representações posicionaram-se, articulando conceitos, terminologias e definições que, além de polêmicas, foram bastante disputadas durante as negociações em Viena.

Já no Preâmbulo do Protocolo, o texto evolutivo A/AC.254/4/Add.1/Rev.1 destaca, dentre outros, a preocupação com o aumento da introdução clandestina de migrantes; o uso indevido da legislação de refúgio em procedimentos migratórios; o custo do resgate, atenção médica, alimentação, alojamento e transporte de migrantes irregulares; o vínculo do contrabando de migrantes a outras atividades delitivas; a necessidade de respeito à soberania e integridade territorial dos Estados $^{36}$.

A proposta referida incluía várias outras alíneas que reforçam o interesse dos Estados receptores de migrantes. Quando se fala dos direitos dos refugiados, por exemplo, lembra-se que a introdução clandestina de imigrantes pode prejudicar as petições de asilo, o que embaralha conceitos como migração, asilo e refúgio. Já a proteção aos migrantes surge como prerrogativa visivelmente desequilibrada quando comparada às ameaças supostamente sofridas pelos Estados-nacionais diante do fenômeno do contrabando e da referida "delinquência organizada" a ele relacionado.

Ademais, a associação da introdução dos migrantes às noções de soberania, crime e segurança nacional é freneticamente enfatizada. Na proposição do Preâmbulo, uma delegação chegou, inclusive, a sugerir que se complementasse o texto com "disposições que sublinhassem as consequências à segurança nacional que teriam o tráfico ilícito e a introdução clandestina de migrantes, além da necessidade de se reforçar a cooperação e coordenação entre os Estados", o que não foi aprovado.

Esta primeira proposição de Preâmbulo sofreu reações de diferentes delegações. Algumas delas sugeriram a inclusão de disposições que abordassem as causas fundamentais do tráfico ilícito de migrantes e que reafirmassem o

constituir una fuente de inspiración útil, pero que la redacción del texto del presente instrumento no debería verse condicionada necesariamente por dicha circular" (ibidem, p. 479).

${ }^{35}$ A tradução da palavra "smuggling" para outras línguas também foi aparentemente polêmica durante as negociações. Segundo consta dos "Travaux Préparatoirs", "durante el debate que tuvo lugar en el primer periodo de sesiones del Comité Especial, varias delegaciones plantearon la cuestión de la traducción del término inglés 'smuggling' a los otros idiomas y de los problemas que ello creaba. Se convino por tanto, en que se prestaría atención a la cuestión de determinar el término apropiado que se emplearía en los idiomas distintos del inglés" (ibidem, p. 478).

${ }^{36}$ Ibidem, p. 479. 
princípio da livre circulação de pessoas ${ }^{37}$. Outras demandaram uma abordagem mais incisiva acerca dos direitos dos refugiados, pleiteando que a Convenção de 1951 e o Protocolo de 1967 não fossem ameaçados pelo instrumento outrora em discussão.

Assim como no caso do Protocolo contra o Tráfico de Pessoas, as discordâncias mais acentuadas entre as posições de diferentes delegações sobressaem-se no âmbito das definições. Na proposta original feita por Áustria e Itália, intencionava-se tipificar o tráfico de migrantes de forma bastante abrangente, como toda e qualquer forma de introdução de pessoas em outro país ${ }^{38}$.

A delegação mexicana reagiu a esta proposição, buscando estender aos familiares dos migrantes a não responsabilização pelo crime de "tráfico e transporte ilícito de migrantes" e reiterando que "não deveria ser punido o migrante que houvesse sido introduzido ou tivesse tentado introduzir de maneira ilícita em um território estrangeiro", com a extensão da não punição àqueles que "tenham obtido ou tentado obter sua residência de maneira ilícita mediante a introdução clandestina de migrantes" ${ }^{\prime 39}$.

Esta reação mexicana parece ter causado certo impasse nas negociações, o que deu lugar a uma discussão específica sobre imunidade dos imigrantes. Segundo consta dos Trabalhos Preparatórios, "várias delegações expressaram inquietude pelo fato do Protocolo poder outorgar imunidade aos imigrantes ilegais, sobretudo se estes eram culpados pelo delito de introduzir clandestinamente outros imigrantes ilegais" ${ }^{\prime 4}$.

Relevante, neste caso, é perceber como a proposição mexicana acabou alterando o conteúdo das próprias discussões do Protocolo. De uma noção de "smuggling" mais ou menos restritiva, posta em debate inicialmente pelos países europeus, passa-se a um questionamento sobre a potencial imunidade dos imigrantes que cometem qualquer tipo de crime. No centro das controvérsias, está a associação quase automática entre migrante e delito, seja na figura do "contraventor de fronteiras" seja na possibilidade deste potencial "criminoso" vir a se tornar imune às demais punições estabelecidas pelo direito interno dos Estados-nacionais. A naturalidade da associação entre migração e criminalidade, neste caso, é notória.

\footnotetext{
37 Ibidem, p. 479.

${ }^{38}$ Segundo a proposta, "Toda persona que intencionalmente y en provecho propio facilite, de forma repetida y organizada, la entrada ilegal de personas en otro Estado del que tales personas no sean nacionales ni residentes permanentes, cometerá el delito de "tráfico y transporte ilícito de migrantes" en el sentido que le otorga el presente Protocolo" (ibidem, p. 491)".

39 Ibidem, p. 510.

${ }^{40}$ Ibidem.
} 
Assim como no Protocolo Anti-Tráfico, o Protocolo contra o Contrabando de Migrantes também mostra um desequilíbrio patente entre medidas de assistência aos imigrantes e outras destinadas ao reforço e seguridade das fronteiras dos países. O Protocolo reserva apenas o artigo 16 para a discussão de proteção e assistência, enquanto medidas de fortalecimento fronteiriço são propostas em quatro outros artigos, em conjunto com tratados de readmissão e sanções contra empresas de transporte que se abstiverem de verificar os documentos de viagem requeridos para a entrada no Estado receptor. Os artigos 12 e 13, por sua vez, pautam exclusivamente a questão da seguridade, controle e legitimidade dos documentos de viagem.

Nas discussões sobre a "repatriação dos migrantes objetos de tráfico ilícito", por seu turno, fica evidente a tensão entre as delegações de países receptores e emissores de migrantes. Enquanto a proposta dos países receptores para o artigo 18 era de que os Estados Parte "facilitassem e aceitassem, sem demora, o retorno das pessoas introduzidas clandestinamente no território de um Estado receptor" ${ }^{\prime \prime 1}$, países como as Filipinas pediam a inclusão de um novo parágrafo que fizesse referência aos direitos dos migrantes e a sua condição de vítimas ${ }^{42}$.

Além disso, enquanto as delegações austríaca e italiana queriam que o artigo 15 não afetasse as obrigações contraídas através de outro acordo bilateral ou multilateral de repatriação de pessoas, a delegação do Marrocos pedia a inclusão da expressão "levando em conta os desejos dos mesmos" à alínea que tratava da proposição de acordos bilaterais para a repatriação de migrantes ${ }^{43}$.

Finalmente, uma última importante disputa nas negociações do Protocolo contra o Contrabando de Migrantes diz respeito ao direito de asilo. Durante o processo de negociação, um número importante de atores e agências internacionais, dentre elas o próprio ACNUR, reconheceram o perigo de eventuais limitações aos direitos e oportunidades dos solicitantes de asilo. Eles argumentavam que a irregularidade da entrada ou presença em um país estrangeiro não poderia afetar os pedidos de asilo. Os migrantes contrabandeados ou pessoas traficadas deveriam, assim, ter todo o direito de apresentar sua requisição de asilo ou de permanência no país de destino.

Diante dessas colocações, os Estados acordaram a inclusão, em ambos os Protocolos, de uma cláusula de salvaguarda afirmando que nada do disposto na Convenção afetaria as obrigações e responsabilidades de indivíduos e Estados no que diz respeito à execução da Convenção sobre o Estatuto dos Refugiados de 1951 e seu Protocolo de 1967. A simples necessidade de elaboração desta cláusula mostra a tensão entre os princípios de "livre circulação" e "reforço do

\footnotetext{
41 Ibidem, p. 577.

42 Ibidem, p. 578.

43 Ibidem, p. 579.
} 
controle fronteiriço", que assumia um tom de ameaça a conquistas sensíveis da comunidade internacional, como os direitos de petição de asilo/refúgio ${ }^{44}$.

Assim, em um processo que chamo de "coyotização das migrações internacionais", os amplos debates referidos à realidade migratória de distintos grupos e indivíduos transformou-se em uma discussão polarizada entre "soberania nacional" vs. "direitos fundamentais dos migrantes". Neste caso, o tema das migrações transfronteiriças passou a ser sistematicamente lido numa ótica criminal e através de conceitos como "contrabando de migrantes" e "violação de fronteiras".

Pode-se dizer que a fundamentação do Protocolo contra o Tráfico Ilícito de Migrantes por Terra, Mar e Ar está baseada em uma perspectiva binária na qual uma linha tênue marca as distinções entre atividades legais e ilegais, entre contrabandista e migrante, entre tráfico e contrabando ${ }^{45}$. A consequência disso é o deslocamento das discussões sobre migração para uma seara criminal, com todos os impactos negativos que isso acarreta para a vida de migrantes, refugiados e pessoas estigmatizadas em seus processos de deslocamento.

\section{Considerações Finais}

No âmbito internacional, a Convenção das Nações Unidas contra o Crime Organizado Transnacional marca a transposição para a estrutura criminal da ONU de questões referidas à mobilidade humana e que antes eram tratadas essencialmente na esfera de Convenções de Direitos Humanos e do Trabalho. Os Protocolos contra o Tráfico de Pessoas e o Contrabando de Migrantes serviram, assim, para deslocar os debates sobre mobilidade humana para a estrutura criminal da instituição, reforçando a lógica de governança das fronteiras e a confluência entre migração e segurança.

Tal processo resulta da associação entre migração e justiça criminal disseminada ao longo da década de 1990 e responde às preocupações de países do hemisfério norte diante do afluxo mais acentuado de pessoas em direção a seus territórios. Nas negociações dos referidos Protocolos, este processo se mostra evidente. Se os temas "tráfico de pessoas" e "contrabando de migrantes" não tinham qualquer relevância nas discussões internacionais sobre crime organizado empreendidas pela ONU a partir da década de 1970, na década de 1990 eles

\footnotetext{
${ }^{44}$ Reis lembra que "no âmbito geral dos direitos humanos, apesar de suas limitações, as convenções relativas aos refugiados e apátridas representam um ponto de inflexão no direito internacional, pois pela primeira vez é reconhecida a existência dos indivíduos no cenário internacional. Lentamente, direitos individuais universais independentes do Estado vão sendo reconhecidos, numa tendência que vinha se acentuando desde o fim da Segunda Guerra Mundial" (REIS, Rossana Rocha. Soberania, direitos humanos e migrações internacionais, p. 151).

${ }^{45}$ VELASCO, Soledad. Desmontando ilusiones: el tráfico de migrantes 'irregularizados' más allá del crimen, el sentido común y los ilegalismos.
} 
se transformaram em Protocolos formais vinculados a uma Convenção criminal, sendo alçados à condição de interesse central da agenda internacional.

Embora apresentados com uma roupagem de direitos humanos e defesa das vítimas, estes instrumentos reiteram a aproximação entre migração e segurança, corroborando práticas de criminalização e controle migratório. Com eles, as discussões acerca da criminalidade internacional passaram a incidir de forma sistemática sobre o fenômeno da mobilidade humana internacional, ajudando a difundir uma visão ambígua e sinuosa do fenômeno migratório que mescla práticas de criminalização da mobilidade e ideais de "proteção das vítimas" e "controle fronteiriço"46.

Portanto, ainda que a relação entre migração e crime/segurança seja coetânea à formação do Estado-nacional moderno e à codificação dos sistemas de justiça criminal a ele referidos, o transbordamento de uma linguagem criminal em direção a assuntos afetos à mobilidade humana passou a ocorrer de forma mais consensual e vigorosa a partir da década de 1990. Este processo resultou na negociação e assinatura de Protocolos que endereçam temas como tráfico de pessoas e contrabando de migrantes, com a mobilização de discursos e práticas de organizações internacionais especializadas no combate ao crime.

$O$ resultado de tal arranjo não tem sido um mundo mais seguro para migrantes ou pessoas com práticas acentuadas de deslocamento voluntário ou forçado. O que se nota, ao contrário, é a falência de distintas organizações internacionais, estatais e supranacionais no acolhimento e recepção de imigrantes e refugiados, e a consolidação de verdadeiras tragédias humanitárias em contextos tidos como sensíveis à "democracia" e aos "direitos humanos"47. Creditar a persistência desses acontecimentos a traficantes ou contrabandistas de pessoas apenas endossa a percepção política estreita que insiste em aproximar migração, crime e segurança, ignorando as complexidades inerentes aos deslocamentos humanos contemporâneos.

\section{Referência bibliográfica}

AUSSERER, Caroline. Controle em nome da proteção: análise crítica dos discursos sobre o tráfico internacional de pessoas. Dissertação de Mestrado do Programa de Pós-Graduação em Relações Internacionais do Centro de Ciências Sociais. Rio de Janeiro: PUC-Rio, 2007.

\footnotetext{
${ }^{46}$ DIAS, Migração e Crime..., op. cit.

47 Finalizo este artigo após me deparar com a terrível notícia, amplamente veiculada pela mídia internacional e nacional, de um caminhão frigorífico apreendido no dia 27 de agosto na Áustria com mais de 70 corpos de imigrantes em decomposição. Os corpos estavam em um caminhão que provavelmente provinha da Hungria e quefoi abandonado na parte leste do território austríaco. É irônico e triste que essa tragédia ocorra justamente na Áustria, centro das discussões internacionais sobre migração, segurança e criminalidade realizadas nas décadas de 1990 e 2000.
} 
BASSIOUNI, M. Cherif; VETERE, Eduardo. Organized Crime: a Compilation of U.N. Documents 1975-1998. New York: Transnational Publishers, 1998.

BERNSTEIN, Elizabeth. Carceral politics as gender justice? The "traffic in women" and neoliberal circuits of crime, sex, and rights. Theory and Society, v. 41, n. 3, 2012, p. 233-259.

BERNSTEIN, Elizabeth. Militarized Humanitarianism Meets Carceral Feminism: The Politics of Sex, Rights, and Freedom in Contemporary Antitrafficking Campaigns. Signs: Journal of Women in Culture and Society, v. 36, n. 1, 2010, p. 45-71.

BROLAN, Claire. An analysis of the human smuggling trade and the Protocol against the Smuggling of Migrants by Land, Air or Sea (2000) from a refugee protection perspective. International Journal of Refugee Law, v. 14, n. 4, 2002, p. 561-596.

BUSS, Doris; HERMAN, Didi. Globalizing Family Values: The Christian Right in International Politics. Minneapolis: Universityof Minnesota Press, 2003.

CASTILHO, Ela W. V. Tráfico de pessoas: da Convenção de Genebra ao Protocolo de Palermo. In Plano Nacional de Enfrentamento ao Tráfico de Pessoas. Brasília: Ministério da Justiça, Secretaria Nacional de Justiça, 2008.

DIAS, Guilherme M. Migração e Crime: desconstrução das políticas de segurança e tráfico de pessoas. Tese de doutorado em Antropologia Social. Campinas: Universidade Estadual de Campinas, 2014.

DIAS, Guilherme M.; SPRANDEL, Marcia A. Transatlantic Journeys: na exploratory research on human trafficking from Brazil to Italy and Portugal. Vienna: ICMPD, 2011.

DOEZEMA, Jo. Now you see her, now you don't: sex workers at the UN Trafficking Protocol negotiation. Social \& Legal Studies, v. 14, n. 1, 2005, p. 61-89.

GALLARGHER, Anne. Human Rights and the new UN Protocols on Trafficking and Migrant Smuggling: a preliminary analysis. Human Rights Quarterly, v. 23, 2001, p. 975-1004.

GALLARGHER, Anne. Trafficking, smulggling and human rights: tricks and treaties. Forced Migration Review, n. 12, January 2002, p. 25-28.

HERZ, Mônica; HOFFMAN, Andrea R. Organizações Internacionais: história e práticas. Rio de Janeiro: Elsevier, 2004.

JORDAN, Ann D. Human Rights or Wrong? The Struggle for a Rights-Based Response to Trafficking in Human Beings. Gender and Development, Oxford: Oxfam, v. 10, n. 1, 2002, p. 28-37.

KEMPADOO, Kamala. Mudando o debate sobre o tráfico de mulheres. Cadernos Pagu, Campinas, UNICAMP, v. 25, 2005, p. 55-78.

PISCITELLI, Adriana G. Entre as máfias e a ajuda: a construção de conhecimento sobre tráfico de pessoas. Cadernos Pagu, Campinas, UNICAMP, v. 31, 2008, p. 29-63.

PISCITELLI, Adriana G. Procurando vítimas do tráfico de pessoas: brasileiras na indústria do sexo na Espanha. REMHU - Revista Interndisciplinar da Mobilidade Humana, Tráfico de Pessoas, n. 37, 2011, p. 11-26.

REIS, Rossana Rocha. Soberania, direitos humanos e migrações internacionais. Revista 
Brasileira de Ciências Sociais, v. 19, n. 55, 2004, p. 149-164.

VLASSIS, Dimitri. Overview of the provisions of the United Nations Convention Against Transnational Organized Crime and its Protocols. In UN. Resource Material Series, n. 59, 2000.

UNITED NATIONS ON DRUGS AND CRIME (UNODC). Convenção contra o Tráfico Ilícito de Entorpecentes e de Substâncias Psicotrópicas. 1988.

UNITED NATIONS ON DRUGS AND CRIME (UNODC). Convenção das Nações Unidas contra o Crime Organizado Transnacional. 2000.

UNITED NATIONS ON DRUGS AND CRIME (UNODC). Protocolo Adicional à Convenção das Nações Unidas contra o Crime Organizado Transnacional Relativo à Prevenção, Repressão e Punição do Tráfico de Pessoas, em Especial Mulheres e Crianças. 2000.

UNITED NATIONS ON DRUGS AND CRIME (UNODC). Protocolo Adicional à Convenção das Nações Unidas contra o Crime Organizado Transnacional, relativo ao Combate ao Tráfico de Migrantes por Via Terrestre, Marítima e Aérea. 2000.

UNITED NATIONS ON DRUGS AND CRIME (UNODC). Travaux Préparatoires de las negociaciones para la elaboración de la Convención de las Naciones Unidas contra la Delincuencia Organizada Transnacional y sus Protocolos. Nueva York, 2008.

UNITED NATIONS ON DRUGS AND CRIME (UNODC). UNODC Chief praises murdered magistrates who helped found modern approach to organized crime. 2012.

VELASCO, Soledad. Desmontando ilusiones: el tráfico de migrantes 'irregularizados' más allá del crimen, el sentido común y los ilegalismos. Apresentación en la Mesa Redonda Políticas Públicas en Torno a la Trata de Personas y el Tráfico de Migantes: Desafíos para sua Formulación y Implementación. Flacso, Quito, 28 de mayo de 2015.

\section{Abstract}

\section{Notes on the negotiations of the "Crime Convention" and of the Protocols on Human Trafficking and Migrant Smuggling}

This article reflects on the negotiation process of the Protocols against Human Trafficking and Migrant Smuggling in the United Nations Convention against Transnational Organized Crime (2000). Based on data from qualitative research and archives, this paper discusses the role of these documents in relocating the migration topic to the criminal apparatus of the United Nations, as well as the consequent process of the convergence of human mobility and criminal justice in the scope of international legislation. This paper discusses some of the behind-the-scenes elements of these negotiations, and shows how the different countries and pressure groups are involved in the process.

Keywords: human trafficking, migrant smuggling, United Nations, migration, human mobility. 
Notas sobre as negociações da "Convenção do crime" e dos Protocolos Adicionais sobre TP e CM

Recebido para publicação em 04/08/2015 Aceito para publicação em 22/10/2015

Received for publication in August, 04 $4^{\text {th }}, 2015$ Accepted for publication in October, 22 $2^{\text {th }}, 2015$

ISSN impresso 1980-8585

ISSN eletrônico 2237-9843

http://dx.doi.org/10.1590/1980-85852503880004511 